\title{
КРАТКИЙ ОБЗОР ЭНТОМОФАУНЫ ПЛАСТИНЧАТОУСЫХ ЖУКОВ (COLEOPTERA: SCARABEIDAE) РЕСПУБЛИКИ ТАTAPCTAH
}

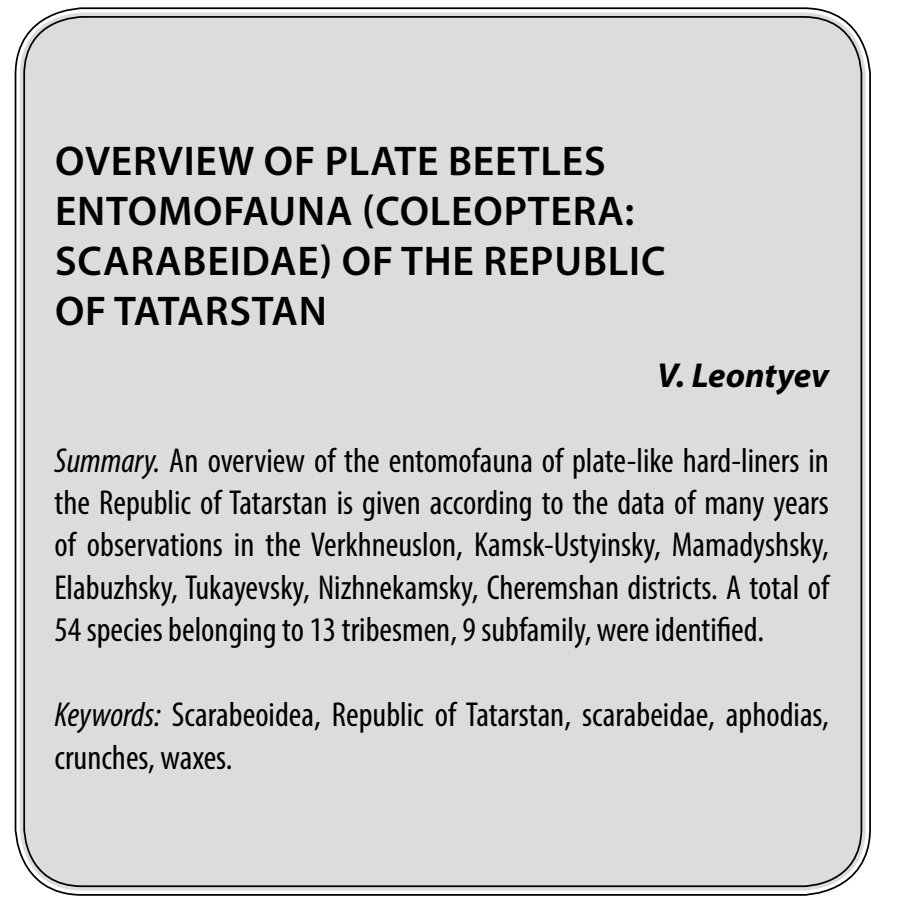

\section{Введение}

$\mathbf{P}$ еспублика Татарстан расположена в восточной части восточно-европейской, или Русской, равнины, у слияния рек Волги и Камы. Её территория включает северную часть Поволжья и соседствует с Предуральем. Территория республики протянулась с запада на восток на 400 км, с севера на юг на 250 км. Площадь республики 68 тыс. км² (Ермолаев и др., 2007). Широкими долинами Волги и Камы равнина разделена на три части: Предволжье, Предкамье и Закамье. Предволжье с максимальными высотами (276 м) занимает северо-восточную часть Приволжской возвышенности. В Восточное Предкамье с севера заходят южные окончания Можгинской и Сарапульской возвышенностей, разделенные долиной р. Иж. Наибольшие высоты достигают здесь 243 м. Самой высокой в Татарстане (до 381 м) является Бугульминская возвышенность в Восточном Закамье. Самый низкий рельеф (до 200 м) характерен для Западного Закамья (Ермолаев и др., 2007).

Республика Татарстан расположена на территории двух природных зон - лесной и лесостепной, в переходной полосе от зоны подзолистых почв к зоне черноземов. Здесь широко распространены дерново-подзолистые, серые лесостепные почвы и черноземы.

\author{
Леонтьев Вячеслав Витальевич \\ К.б.н., дочент, Елабужский институт - филиал \\ Казанского федерального университета \\ vleontev@yandex.ru
}

Аннотация. Приведен краткий обзор энтомофауны пластинчатоусых жесткокрылых в Республике Татарстан по данным многолетних наблюдений в Верхнеуслонском, Камско-Устьинском, Мамадышском, Елабужском, Тукаевском, Нижнекамском, Черемшанском районах. Всего было выявлено 54 вида, относящихся к 13 трибам, 9 подсемействам.

Ключевые слова: Scarabeoidea, Республика Татарстан, пластинчатоусые, афодии, хрущи, восковики.

В данной работе приведен краткий обзор пластинчатоусых жесткокрылых, выявленных по результатам полевых сборов автора в Республике Татарстан на рубеже веков без указания локалитета (в силу ограничений - в следующих публикациях). Сведения о составе энтомофауны пластнчатоусых жуков в различных регионах Среднего Поволжья на рубеже XXI века приводятся в работах многих авторов: А.Ю. Исаев (1995); Г.И. Юферев (2000); Л.В. Егоров (2001, 2004); И.В. Шохин (2002); С. В. Дедюхин (2003) А.Ю. Исаев и др. (2004); А.С. Сажнев, Н. В. Роднев (2006); 3. А. Тимралеев и др. (2007).

\section{Цель исслеАования}

Целью исследования была систематизация и составление списка видов пластинчатоусых жесткокрылых на территории республики.

\section{материал и методы}

Были использованы методы ручного сбора, кошения с травяного покрова, кустарников, ловли на световые источники. Фиксация материала проводилась общепринятыми способами для жесткокрылых насекомых. Номенклатура таксонов Scarabaeoidea приведена по «Catalogue of Palaearctic Coleoptera» (2006) с уточне- 
ниями в свете современных данных. Идентификация и уточнение видов Scarabaeoidea проводилось по отечественным работам: Медведев $(1949,1951,1952,1960$, 1964, 1965), Берлов (1985), Берлов и др. (1989), Николаев (1989), Негробов (2000), Кабаков (2006), Ахметова, Фролов (2014).

\section{Результаты исслеАования и их обсужАение}

Ниже приводим список выявленных видов Scarabaeidae в Республике Татарстан.

Family Scarabaeidae Latreille, 1802

Subfamily Aphodiinae Leach, 1815

Tribe Aphodiini Leach, 1815

Aphodius (Aphodius) fimetarius (Linnaeus, 1758) Афодий краснокрылый (навозный)

A. (Acrossus) depressus (Kugelann, 1792) - А. низкий

A. (Acrossus) luridus (Fabricius, 1775) - А. бледножелтый

A. (Acrossus) rufipes (Linnaeus, 1758) - А. ржавоногий

A. (Agrilinus) ater (De Geer, 1774) - А. темный

A. (Bodiloides) nitidulus (Fabricius, 1792) - А. блестящий

A. (Bodilus) lugens (Creutzer, 1799) - А. траурный

A. (Calamosternus) granarius (Linnaeus, 1767) - A. хлебный

A. (Chilothorax) biguttatus (Dalla Torre, 1879) - A. двупятнистый стрый

A. (Chilothorax) distinctus (O. F. Müller, 1776) - А. пе-

A. (Chilothorax) melanostictus W.L.E. Schmidt, $1840-$ А. темнопятнистый

A. (Colobopterus) erraticus (Linnaeus, 1758) - A. блуждающий

A. (Euheptaulacus) sus (Herbst, 1783) - А.-свинья

A. (Eupleurus) subterraneus (Linnaeus, 1758) - А. подземный

A. (Melinopterus) prodromus (Brahm, 1790) - А.-предвестник

A. (Otophorus) haemorrhoidalis (Linnaeus, 1758) - A. краснозадый

A. (Phalacronothus) quadrimaculatus (Linnaeus, 1761) - А. четырехпятнистый

A. (Rhodaphodius) aestivalis (Stephens, 1839) (=Aphodius (Aphodius) foetens (Fabricius, 1787)) - A. пастбищный

A. (Teuchestes) fossor (Linnaeus, 1758) Афодий-копатель (землекоп)

A. (Volinus) sticticus (Panzer, 1798) (=Aphodius (Chilothorax) sticticus (Panzer, 1798)) - А. пятнистый

Subfamily Scarabaeinae Latreille, 1802
Tribe Coprini Kolbe, 1805

Copris lunaris (Linnaeus, 1758) — Копр лунный

Tribe Oniticellini DeOrbigny, 1916

Euoniticellus fulvus Goeze, 1777 - Навозничек рыжеватый

Tribe Onthophagini Lacordaire, 1856

Caccobius (s.str.) schreberi (Linnaeus, 1767) - Калоед Шребера

Onthophagus (Palaeonthophagus) coenobita (Herbst, 1783) - К.-монах

Onthophagus fracticornis (Preyssler, 1790) - К. слаборогий

Onthophagus furcatus Fabricius, 1781 - К. двурогий

Onthophagus (Palaeonthophagus) gibbulus (Pallas, 1781) - К. горбатый

Onthophagus (Palaeonthophagus) nuchicornis (Linnaeus, 1758) - К. короткорогий

Onthophagus ovatus Linnaeus, 1767 - К. овальный

Onthophagus semicornis Panzer, 1798 - К. полурогий

Onthophagus taurus Schreber, 1759 - К.-бык

Onthophagus vacca Linnaeus, 1767 - К.-корова

Onthophagus vitulus Fabricius, 1777 - К.-бычок

Subfamily Sericinae, 1837

Tribe Sericini Kirby, 1837

Serica brunnea (Linnaeus, 1758) - Серика шелковистая

Subfamily Melolonthinae Macleay, 1819

Tribe Melolonthini Samuelle, 1819

Melolontha hippocastani Fabricius, 1801 - Хрущ майский восточный

Melolontha melolontha (Linnaeus, 1758) - Хрущ майский западный

В последнее время распространяется на восток и рядом авторов вид отмечался значительно восточнее линии, указанной С.И. Медведевым (1965): на севере Воронежской (Негробов и др., 2005), Липецкой (Цуриков, 2009), Тульской (Дорофеев, 2007), Калужской (Алексеев, 2012) областей, в Республике Мордовия (Большаков и др., 2013).

Polyphylla fullo (Linnaeus, 1758) - Хрущ мраморный

Tribe Rhizotrogini Belthold, 1827

Lasiopsis (s. str.) canina (=caninus) (Zoubk., 1829) Корнегрыз-собака

Rhizotrogus (Amphimallon) solstitialis (Linnaeus, 1758) (=Amphimallon solstitiale (Linnaeus, 1758)) — Kopнегрыз (Нехрущ) июньский

\section{Subfamily Rutelinae MacLeay, 1819}


Tribe Anomalini Streubel, 1839

Anisoplia (s.str.) agricola (Poda von Neuhaus, 1761) Кузька-крестоносец

Anisoplia (Autanisoplia) austriaca (Herbst, 1783) Кузька посевной

Anomala dubia (Scopoli, 1763) - Хрущик луговой

Chaetopteroplia segetum (Herbst, 1783) - Кузька-красун

Phyllopertha horticola (Linnaeus, 1758) - Хрущик caдовый

\section{Subfamily Hoplinae, Latreille, 1829}

Tribe Hopliini Latreille, 1829

Hoplia parvula Krynicki, 1832 - Цветоройка малая (гоплия-крошка)

\section{Subfamily Dynastinae MacLeay, 1819}

Tribe Oryctini Mulsant, 1842

Oryctes nasicornis (Linnaeus, 1758) - Жук-носорог обыкновенный (остророгий)

\section{Subfamily Cetoniinae Leach, 1815 \\ Tribe Cetoniini Leach, 1815}

Cetonia aurata (Linnaeus, 1758) - Бронзовка золотистая

Oxythyrea funesta (Poda, 1761) - Бронзовка вонючая (рябая)

Protaetia (Liocola) marmorata (Fabricius, 1792) Бронзовка мраморная

Protaetia (Potosia) metallica (Herbst, 1782) - Бронзовка металлическая

Protaetia (Cetonischema) speciosissima (Scopoli, 1786) (=Protaetia (Cetonischema) aeruginosa (Drury, 1770) - Бронзовка большая зеленая (гладкая)

По мнению некоторых авторов (Krell et al., 2012; Lillig, 2012) вид, ошибочно принимался за Protaetia aeruginosa (Drury, 1770), широко распространенный в Европе, был определен как Protaetia speciosissima (Scopoli, 1786).

\section{Subfamily Trichiinae Gmelin, 1790}

Tribe Osmodermini Schenkling, 1922

Osmoderma barnabita Motschulsky, 1845 (=eremita aисt.) - Восковик-отшельник пахучий

Ранее вид принимался за O. eremita (Scopoli, 1763) [Красная книга ..., 2006], который по мнению некоторых авторов (Audisio et al., 2007) обитает в Западной Европе, а восточная граница ареала проходит от Швеции, через северную Германию до южной Италии; примерно от этой линии, на востоке, на европейской части России встречается другой вид - O. barnabita.

Tribe Trichiini Fleming, 1821

Gnorimus variabilis (Linnaeus, 1758) (= octopunctatus Fabricius, 1775) - Пестряк изменчивый

Trichius fasciatus (Linnaeus, 1758) - Восковик перевязанный

\section{Зак^ючение}

Таким образом, таксономическое распределение пластинчатоусых жесткокрылых в Республике Татарстан выглядело следующим образом.

Подсемейство Aphodiinae включало одну трибу Aphodiini в составе которой было выявлено 20 видов.

Подсемейство Scarabaeinae включало 3 трибы (Coprini, Oniticellini, Onthophagini), к которым относились 13 видов.

Подсемейство Sericinae включало трибу Sericini c 1 видом.

K подсемейству Melolonthinae относились 2 трибы (Melolonthini, Rhizotrogini) с 5 видами.

Подсемейство Rutelinae включало 5 видов, относящихся к трибе Anomalini.

Подсемейство Hoplinae включало один вид, относящийся к трибе Hopliini.

Подсемейство Dynastinae также включало один вид, относящийся к трибе Oryctini.

Подсемейство Cetoniinae включало 5 видов, относящихся к трибе Cetoniini.

Подсемейство Trichiinae включало 3 вида, относящихся к трибам Osmodermini и Trichiini.

В целом, можно обобщить, что в Республике Татарстан пока выявлено 54 вида, относящихся к 13 трибам, 9 подсемействам. Список видов не является исчерпывающим, для восполнения которого требуются специальные исследования. Вероятно, возможно обнаружение в республике более 80 видов пластинчатоусых жесткокрылых. 


\section{ЛИТЕРАТУРА}

1. Алексеев С. А. Дополнение к фауне пластинчатоусых жуков (Coleoptera: Scarabaeidae) заповедника «Калужские засеки» // Тр. заповедника «Калужские засеки». Вып. 2. Калуга, 2012. С. 121-124.

2. Ахметова Л.А., Фролов А. В. Обзор пластинчатоусых жуков трибы Aphodini (Coleoptera, Scarabeidae) фауны России // Энтомологическое обозрение. XCIII, 2, 2014. С. 403-446.

3. Берлов Э. Я. Определитель жуков-копрофагов рода Aphodius Illig. Прибайкалья // Наземные членистоногие Сибири и Дальнего Востока. Иркутск: Изд-во Иркут. гос. ун-та, 1985. С. 23-35.

4. Берлов Э.Я., Калинина 0. И., Николаев Г. В. Семейство Scarabaeidae - Пластинчатоусые // Определитель насекомых Дальнего Востока СССР. Т. III, Часть 1. Л: Наука, 1989. С. 380-434.

5. Большаков Л.В. и др. Расселение майского жука западного Melolontha melolontha (Linnaeus, 1758) (Coleoptera: Scarabeidae) в центре европейской России / Л. В. Большаков, С. К. Алексеев, А. П. Михайленко, С. Г. Мазуров // Труды Мордовского государственного природного заповедника имени П. Г. Смидовича. Вып. ХІ. Саранск; Пушта, 2013. С. 89-97.

6. Дедюхин С. В. Пластинчатоусые жесткокрылые (Coleoptera, Scarabaeoidea: Trogidae, Scarabaeidae, Lucanidae) Удмуртской Республики // Бюл. МОИП. Сер. Биология. 2003. Т. 108, вып. 6. С. 3-13.

7. Дорофеев Ю. В. Список видов жесткокрылых (Hехароda: Coleoptera) Тульских засек // Природа Тульской области. Сб. науч. тр. Вып.1. Тула, 2007. С. 22-58.

8. Егоров Л. В. Новые и редкие для фауны Чувашии виды жесткокрылых насекомых (Insecta, Coleoptera) // Вестник ЧГПУ им. И. Я. Яковлева. Чебоксары, 2004. № 4(42). С. 162-175.

9. Егоров Л. В. Состояние изученности колеоптерофауны Чувашской Республики на рубеже веков // Вестник ЧГПУ им. И.Я. Яковлева. Чебоксары, 2001. № 1(20). C. 47-59.

10. Ермолаев 0.П. и др. Ландшафты Республики Татарстан: региональный ландшафтно-экологический анализ / 0. П. Ермолаев и др.; под ред. проф. 0. П. Ермолаева. Казань: Слово, 2007. 410 c.

11. Исаев А.Ю. К познанию фауны пластинчатоусых жуков (Coleoptera, Lamellicornia: Lucanidae, Trogidae, Scarabaeidae) Ульяновской области // Насекомые Ульяновской области. Ульяновск, 1995. Ч. 2. С. 28-45.

12. Исаев А.Ю., Егоров Л. В., Егоров К. А. Жесткокрылые (Insecta, Coleoptera) лесостепи Среднего Поволжья: Каталог. Ульяновск, 2004. 72 с.

13. Кабаков 0. Н. Пластинчатоусые жуки подсемейства Scarabaeinae (Insecta: Coleoptera: Scarabaeidae) фауны России. М., 2006. 374 с.

14. Кабаков 0. Н. Пластинчатоусые жуки подсемейства Scarabaeinae фауны России и сопредельных стран М.: Товарищество научных изданий КМК, 2006.374 с.

15. Красная книга Республики Татарстан: животные, растения, грибы / под гл. ред. А. А. Назиров, зам. гл. ред. Ю. А. Горшков, Д. В. Иванов, Т. В. Рогова. 3-е изд. Казань: Изд-во «Идел-Пресс», 2016.760 c.

16. Медведев С. И. Пластинчатоусые (Scarabaeidae): подсемейства Cetoniinae, Valginae // Фауна СССР: Н.С. № 90. Жесткокрылые; Т. 10. Вып. 5. М.-Л.: Наука, 1964. $375 \mathrm{C}$.

17. Медведев С. И. Пластинчатоусые (Scarabaeidae): подсемейства Euchirinae, Dynastinae, Glaphyrinae, Trichiinac // Фауна СССР: Н.С. № 74. Жесткокрылые. T. 10. Вып. 4. М.-Л.: Наука, 1960.400 c.

18. Медведев С. И. Пластинчатоусые (Scarabaeidae): подсемейство Melolonthinae (Хрущи). Ч. 1. // Фауна СССР: Н.С. № 46. Жесткокрылые. Т. 10. Вып. 1. М.-Л.: Наука, 1951. 514 с.

19. Медведев С. И. Пластинчатоусые (Scarabaeidae): подсемейство Melolonthinae (Хрущи). Ч. 2. // Фауна СССР: Н.С. № 52. Жесткокрылые. Т. 10. Вып. 2. М.-Л.: Наука, 1952. 280 с.

20. Медведев С. И. Пластинчатоусые (Scarabaeidae: подсемейства Rutelinae (Хлебные жуки и близкие группы) // Фауна СССР: Н.С. № 36, Жесткокрылые; Т. 10. Вып. 3. М.-Л.: Наука, 1949. 371 с.

21. Медведев С. И. Семейство Scarabaeidae - Пластинчатоусые // Определитель насекомых Европейской части СССР. Т. II. М.-Л.: Наука, 1965. 668 с.

22. Негробов C.0. К фауне и экологии рогачей и пластинчатоусых жуков (Coleoptera: Lucanidae, Scarabaeidae) Воронежской области // Энтомологическое обозрение. СПБ, 2000. Т. LXXIX, вып. 1. С. 89-95.

23. Негробов С.О., Цуриков М. Н., Логвиновский В. Д., Фомичев А. И., Прокин А. А., Гильмутдинов К. С. Отряд Coleoptera // Кадастр беспозвоночных животных Воронежской области. Воронеж, 2005. С. 534-673.

24. Николаев Г. В. Пластинчатоусые жуки Казахстана и Средней Азии. Алма-Ата: Наука, 1989. 232 с.

25. Николаев Г.В., Пунцагдулам Ж. Пластинчатоусые (Coleoptera, Scarabaeoidea) Монгольской Народной Республики // Насекомые Монголии. Л: Наука,1984. Вып. 9. С. 90-294.

26. Сажнев А.С., Роднев Н. В. К фауне жесткокрылых (Соleoptera) Саратовского района Саратовской области. 2006. // http://www.zin.ru/ANIMALIA/COLEOPTERA/ rus/sarasar1.htm (дата обращения: 15.01.2020)

27. Тимралеев 3.А., Каменев А. Г., Бардин О. Д. Насекомые Мордовии. Ч. ІІ. Жесткокрылые. Саранск, 2007. 176 с.

28. Ццриков М. Н. Жуки Липецкой области. Воронеж, 2009. 332 с.

29. Шохин И. В. Пластинчатоусые жуки (Coleoptera: Scarabaeoidea) Нижнего Поволжья. Биоразнообразие насекомых юго-востока европейской части России. Волгоград, 2002.

30. Юферев Г. И. Отряд Жесткокрылые // Животный мир Кировской области (беспозвоночные животные). Киров, 2000. Т. 5. С. 120-180. 
31. Audisio P. et al. Updating the Taxonomy and Distribution of the European Osmoderma, and Strategies for their Conservation (Coleoptera, Scarabaeidae, Cetoniinae) / P. Audisio, H. Brustel, G. M. Carpaneto, G. Coletti, E. Mancini et al. // Fragmenta entomologica, Roma, 39(2). 2007. P. $273-290$.

32. Catalogue of Palaearctic Coleoptera (Eds. I. Lobl \& A. Smetana). 2006. Volume 3. Stenstrup: Apollo Books. 690 p.

33. Krell F.-T., Rey A., Micy E. \& M. Dutto. On nomenclature and identity of Scarabaeus aeruginosus Linnaeus, S. aerugineus Drury and S. speciosissimus Scopoli (Coleoptera: Scarabaeoidea: Cetoniinae and Rutelinae. Revue Suisse de Zoologie. 2012.119 (1): 99-110.

34. Lillig Martin. Der Große Goldkäfer Protaetia (Cetonischema) speciosissima (Scopoli, 1786) neu im Saarland (Coleoptera: Scarabaeidae: Cetoniinae). Abh. Delattinia 38: 303-306. Saarbrücken. 2012. ISSN0948-6526

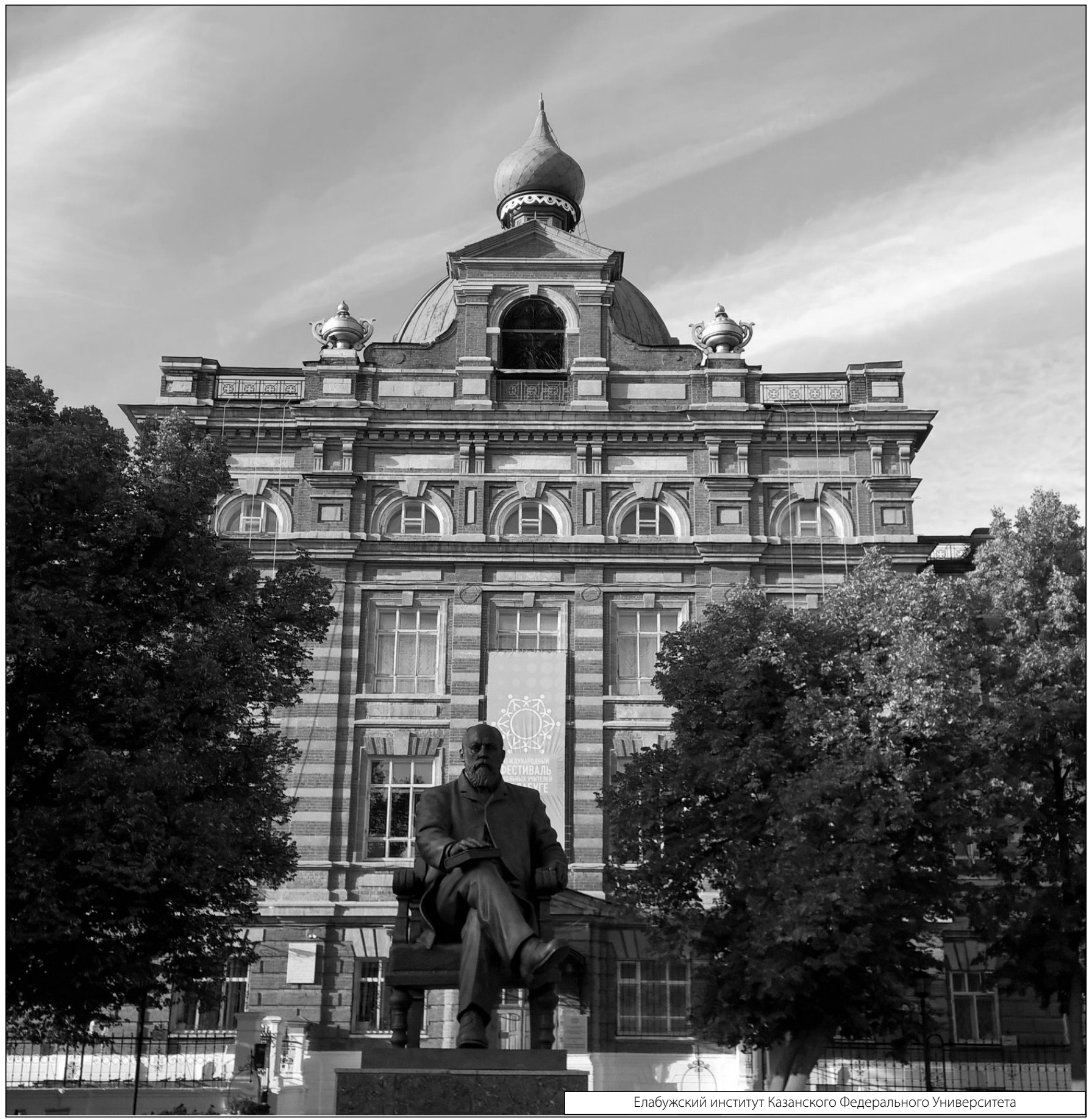

